\title{
A GIS-BASED DRASTIC MODEL: THE BOUMAIZA PLAIN (NORTH-EAST ALGERIA)
}

\author{
Attoui Badra $^{1 *}$, Sayad Lamine ${ }^{2}$, Benrabah Samia ${ }^{1}$, Daoud Rabia ${ }^{3}$ \\ ${ }^{1}$ Laboratory of Geology Badji Mokhtar University-Annaba, Sidi Amar, B.P. 12 Annaba, \\ 2300, Algeria. \\ 2 Departement of Geology, University-Annaba, Sidi Amar, B.P. 12 Annaba, 2300, \\ Algeria. \\ ${ }^{3}$ Hydraulic Department, University of Oum Bouaghi, Algeria. \\ *Corresponding author: badra.attoui@univ-annaba.dz; att.badra@yahoo.fr
}

Keywords: Boumaiza Plain, vulnerability, Algeria, DRASTIC, GIS.

\begin{abstract}
.
The plain of Boumaiza is located in the north east of Algeria in the wilaya of Skikda. This region is characterized by agricultural activity and is subject to a mediterranean climate. This agricultural development is liable to contaminate the groundwater heavily loaded by the local population for its drinking water needs. In order to highlight the state of vulnerability to groundwater pollution of the captive aquifer, which is composed of sands and gravels and pebbles, it is based on a marly substratum, GIS-based DRASTIC Index method has been applied in the aquifer of Boumaiza Plain. This method is presented in the form of numerical rating systems based on consideration of the different factors influencing the hydrogeological system, where a note and a weight are affected and varying with each parameter used. This method is based in the parameters like depth to the groundwater, net recharge, Aquifer media, soil media, topography, impact of the vadose zone, and hydraulic conductivity.

The results show that the study area is characterized by a low and medium vulnerability to pollution.
\end{abstract}

\section{Introduction}

Water pollution is an alteration of the natural qualities (physical and chemical) of water. It is both the action and the processes of degradation of the qualities of water (Chaoui et al 2015). Groundwater pollution poses the permanent risk of limiting this resource in the near future. It results essentially from human activity independently of the natural deterioration related to geological factors (Attoui et al 2012). In this context, the study of the vulnerability to pollution of the aquifer system could prevent the risks of 
contamination and oriented the guide the management and exploitation of groundwater Daty (1997).

\section{STUDY AREA}

The plain of Boumaiza also called captive champion of Guerbès is located in the North East of Algeria in the wilaya of Skikda. It belongs to the "Constantine Center coastal watersheds". And represents a large part of the subbasin (Lake Fetzara) according to the nomenclature of the Agence des Bassins Hydrograpgiques. It is limited to the north by Lake Fetzara and the Edough massif, to the South by the mountains of Ain Berda, to the West by Jebel Safia and to the East by El Hadjar and El Kantara, Hadj-Said (2007), (Fig. 1).

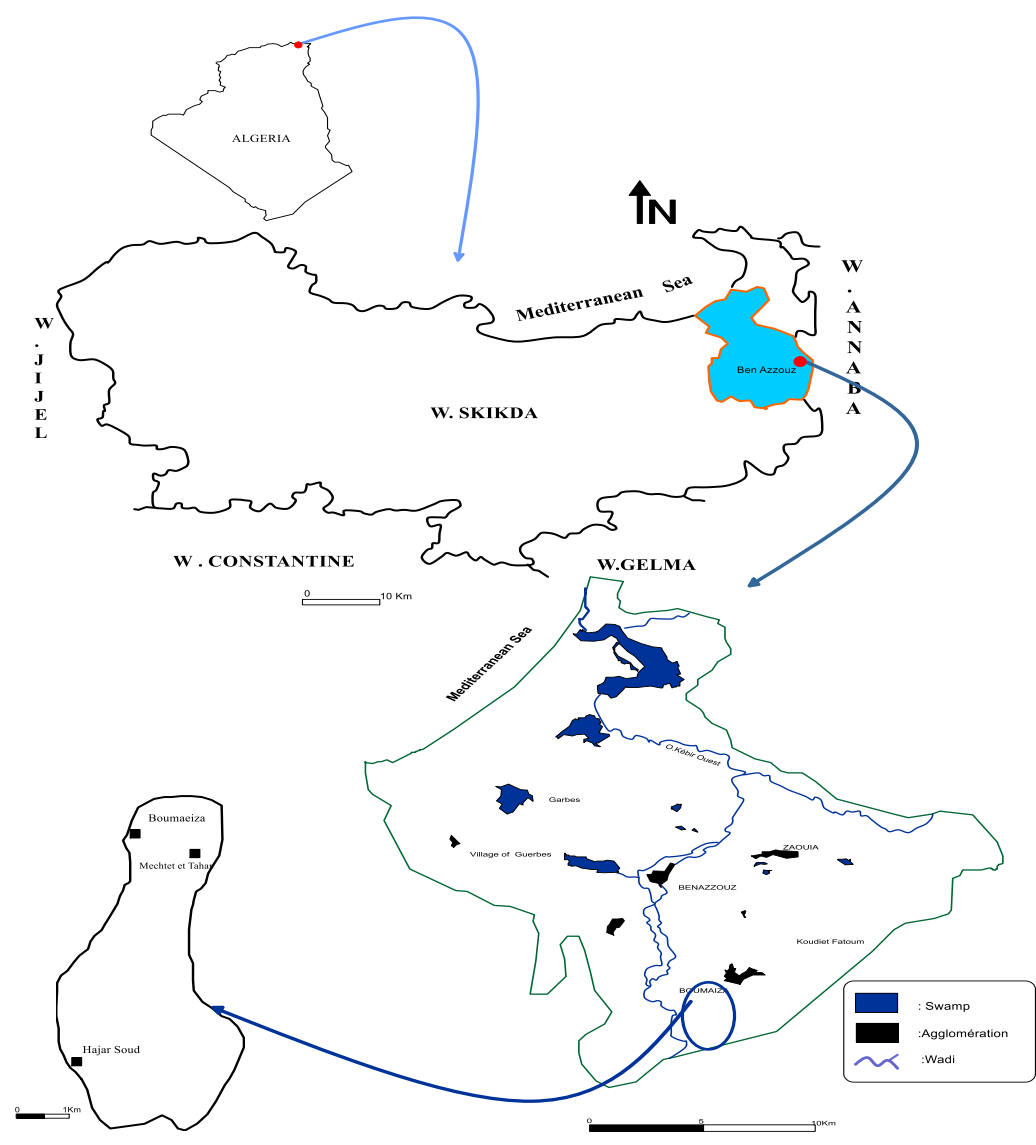

Figure 1. Location of the study area Hadj-Said (2007) 
The lithological sections of the drilling in the Boumaiza sector show that the Boumaiza alluvial aquifer is found in the Quaternary gravels.

\section{METHODS}

DRASTIC model was created in the 1980s by the National Water Well Association following a request from the EPA, The objective was to realize a method of estimating the intrinsic vulnerability applicable to hydrogeological conditions encountered in the USA Baalousha (2010):, The DRASTIC method takes into account seven parameters, each first letter of a parameter constituting the name of this method, Each of the seven parameters is assigned a multiplying factor $(\mathrm{Dp})$ which is increasing from 1 to 5 according to the importance of the parameter for estimating the vulnerability (Abdeslem et al 2017, Aller et al 1987).Then these maps are superposed to produce a resultant layer where the index will be calculated from the DRASTIC vulnerability (ID) according to the equation: $\mathrm{ID}=\mathrm{DpDc}+\mathrm{RpRc}+\mathrm{ApAc}+\mathrm{SpSc}+\mathrm{TpTc}+\mathrm{Iplc}+\mathrm{CpCc}$ With: R: cote $\mathrm{w}$ : weightThe maps superposed will obviously the same cartographic characteristics (Nahin et al 2019),, be the same projecting system, (Attoui et al 2017) the same length units, the same geographic extent and the same resolution, because all calculations will be in matrix format (Sathees et al 2014).

Appreciation of the DRASTIC index is only possible through comparative analysis between different sites.

To this end, the group to associate J.R.B developed in 1982, a representation system offering the user an immediate visualization of the degree of vulnerability, and in 1987 the Canadian R Fréchette updated this representation (Foster 1987). The principle of this representation groups the vulnerability indices into five (05) classes as shown in Figure 2:

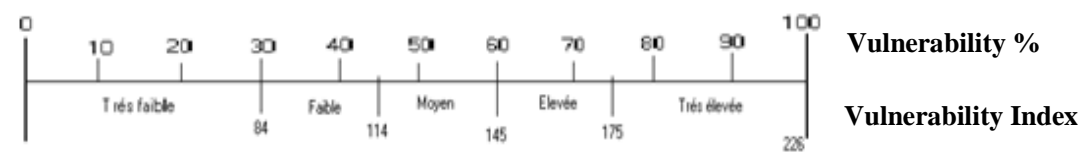

Figure 2. Diagram of vulnerability classes according to the DRASTIC model.

The application of this table consists in dividing the index value of each zone by the maximum value 226 , then multiplying by 100 in order to express the vulnerability in percentage. 


\section{RESULTS AND DISCUSSION}

\subsection{Depth of Water}

The evaluation of this parameter was based on the piezometric measurements, carried out in March 2017. These measurements show that the piezometric level of the aquifer varies between $2 \mathrm{~m}$ and $10 \mathrm{~m}$. These different values make it possible to distinguish two zones (Fig. 3), An area located in the northwest of the plain, where the depth of water is less than $3 \mathrm{~m}$, partial vulnerability index, a value of 45 .

- The second zone (occupies most of the plain), whose water depth varies between 4.5 and $9 \mathrm{~m}$ and partial index of 35 .

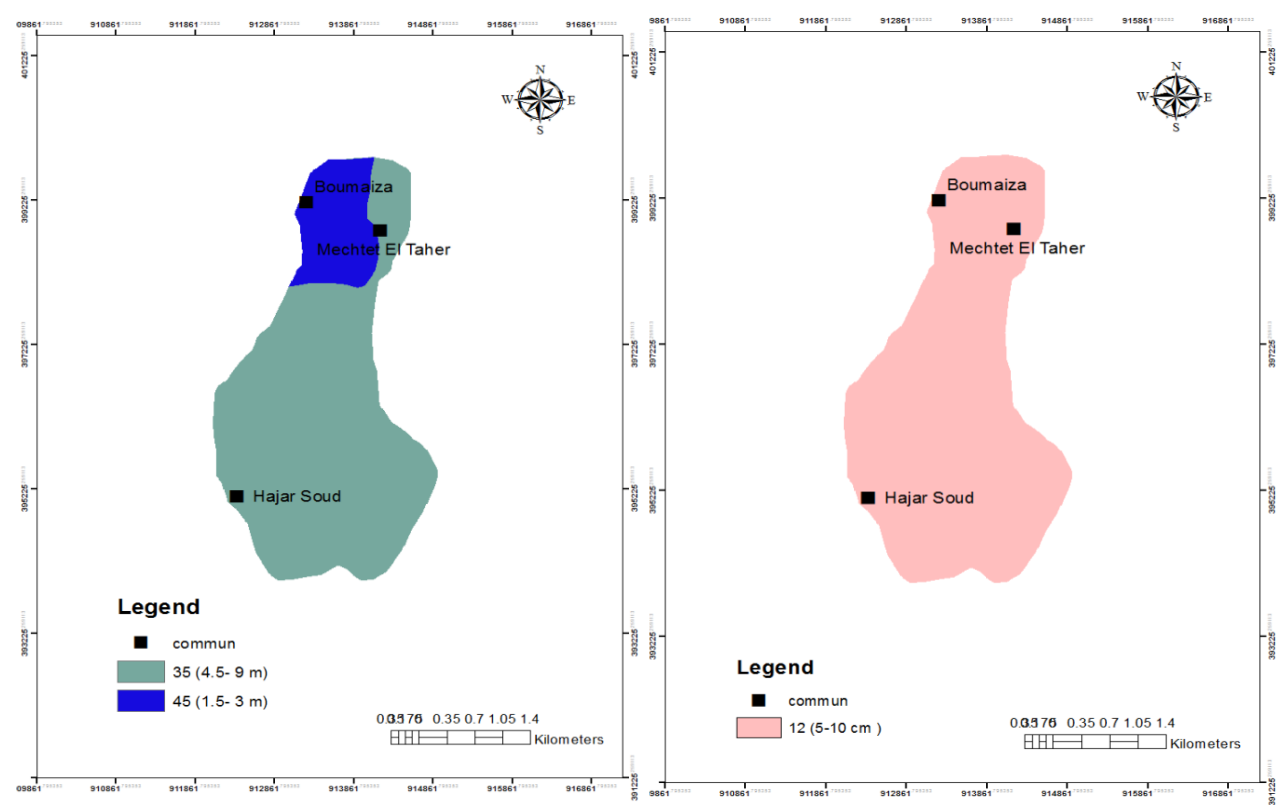

Figure. 3. Depth of groundwater map in study area

Figure 4. Net recharge map in study area

\subsection{Recharge}

The map of the "Net recharge" parameter, thus obtained (Fig. 4), a single area of partial vulnerability indexes (IR) covering the whole plain, or the recharge water slide is of the order of $855,2 \mathrm{~mm} /$ year It is assigned a partial vulnerability index of 12 . 


\subsection{The Aquifer Media:}

The description of the material constituting the saturated and unsaturated zone, was carried out thanks to the explanatory note of the geological sketch of the region and the geologic and lithological sections of the boreholes capturing the aquifer. It appears from the compilation of all these documents, that the filling of the plain consists of a mixture of gravel, sand, pebbles. The permeable material is therefore predominant. In accordance with the sandy and gravelly nature of the aquifer, the map relating to this parameter (Fig.5), shows for all the plain, except for its lateral borders, a "Drastic index" of 24.

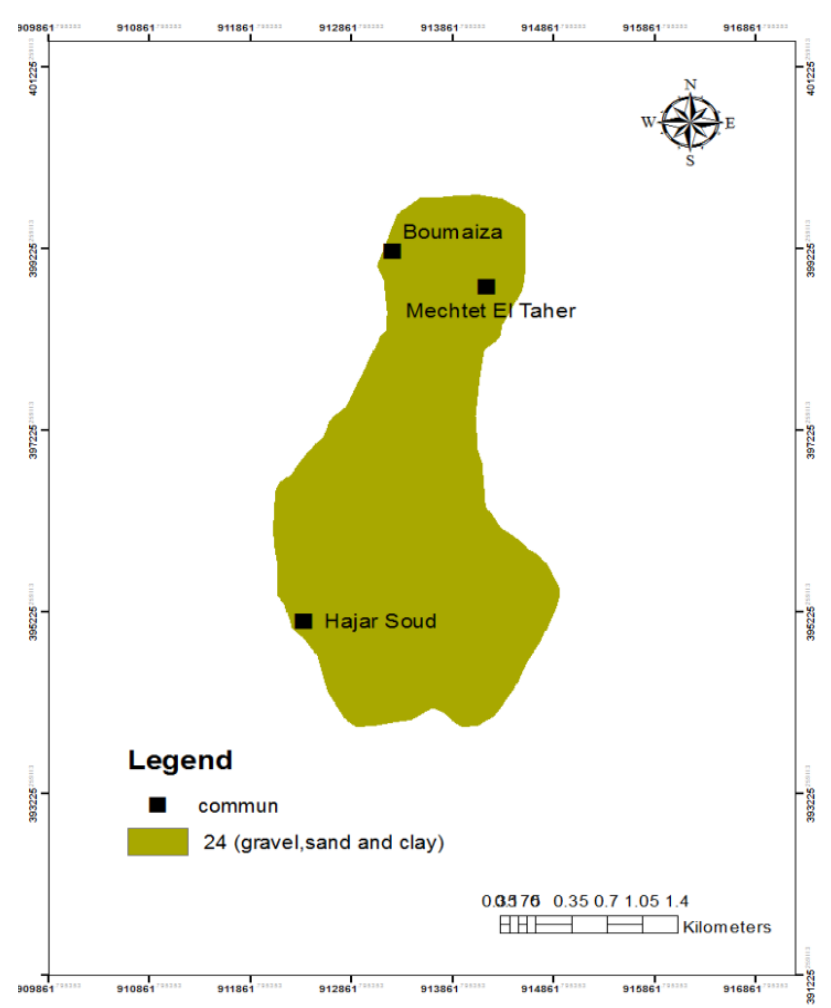

Figure 5. The Aquifer media map in study area

\subsection{The Soil}

The map (Fig. 6) presented two types of soils show:

- Clay soils: covering almost the majority of the plain, constituting a relative protection of the groundwater against the risks of pollution, These soils are assigned a low partial vulnerability index, a value of 2 . 


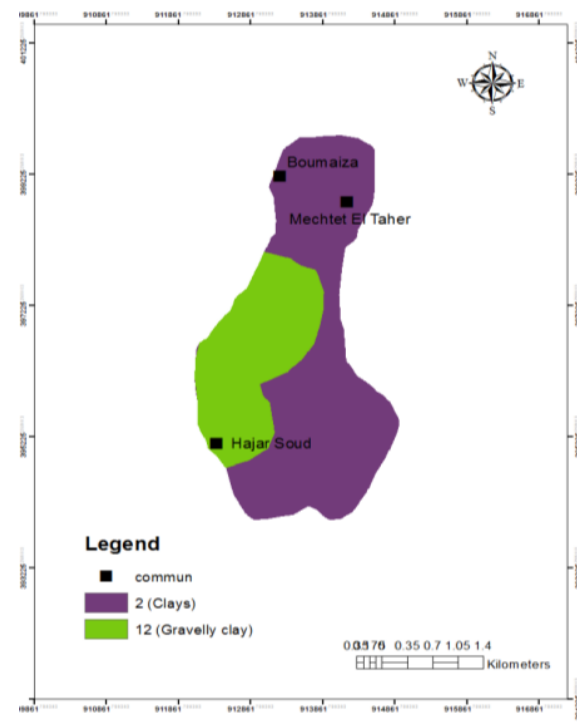

Figure 6. Soil media map in study area

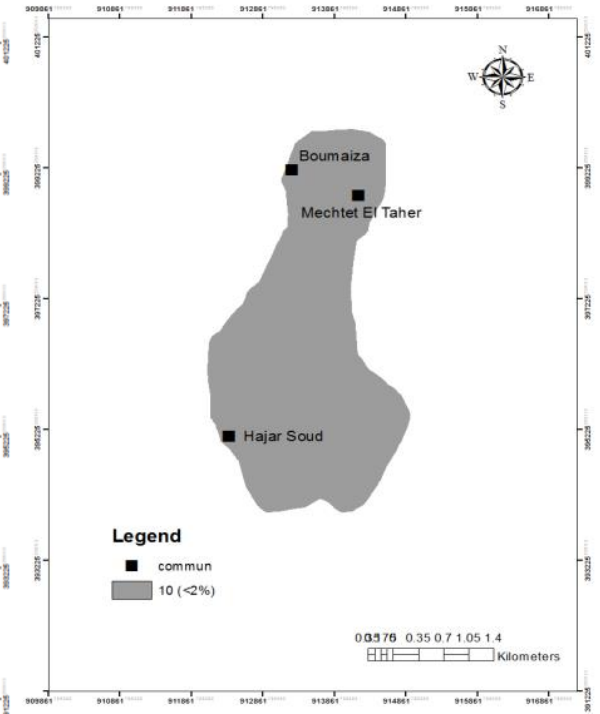

Figure 7. Topography map in study area

- Clay-gravelly soils: more permeable, occupying the middle part of the plain. They are assigned a partial vulnerability index IS $=12$.

\subsection{The topography}

The Boumaiza plain is relatively flat, with low slopes, less than $2 \%$. The slope map was made using topographic maps at 1:25,000 scale from Azzaba. In the map of the "Topography" parameter (Fig. 7), the plain is assigned a partial vulnerability index (IT) of the order of 10.

\subsection{Impact of Vadose Zone}

The Figure 8 shows the existence of a medium vulnerability area, covering most of the Boumaiza plain.In this whole area, the unsaturated zone, consisting essentially of impermeable clay formations, covers almost the entire plain, reflecting a mean partial vulnerability index ( $\mathrm{II}=30)$. And a small part consisting of formations more or less permeable clay-gravel texture, promotes the infiltration of pollutants, which would eventually be discharged to the surface. It is assigned a mean partial vulnerability index $(I I=40)$. 


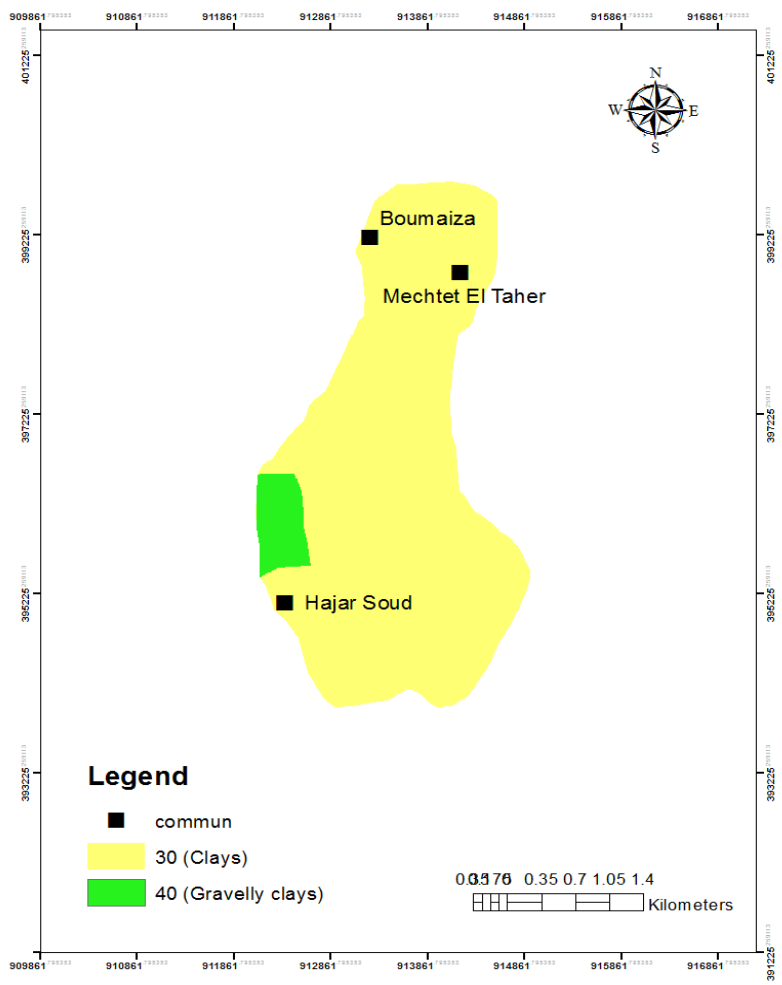

Figure 8. Impact of vadose zone map, in study area

\subsection{Hydraulic Conductivity}

This parameter is evaluated with transmissivity value data and drill logs to estimate permeability.

* Depending on the lithological nature of the aquifer, values of the permeability obtained by this method, which vary from one point to another. Nevertheless, they allow to identify two zones of permeability (Fig. 9), each characterized by its own partial vulnerability index (IC):

-The one occupies almost the whole of the plain characterized by a low permeability, higher than $4.7 * 10-7$ to $4.7 * 10-5 \mathrm{~m} / \mathrm{s}$ ), and thus resulting in a partial index of vulnerability "IC" equal to 3 .

- The other covers a very limited area in the south-west of the plain, with medium permeability $(10-5 \mathrm{~m} / \mathrm{s})$, which is assigned a partial vulnerability index of 6 . 


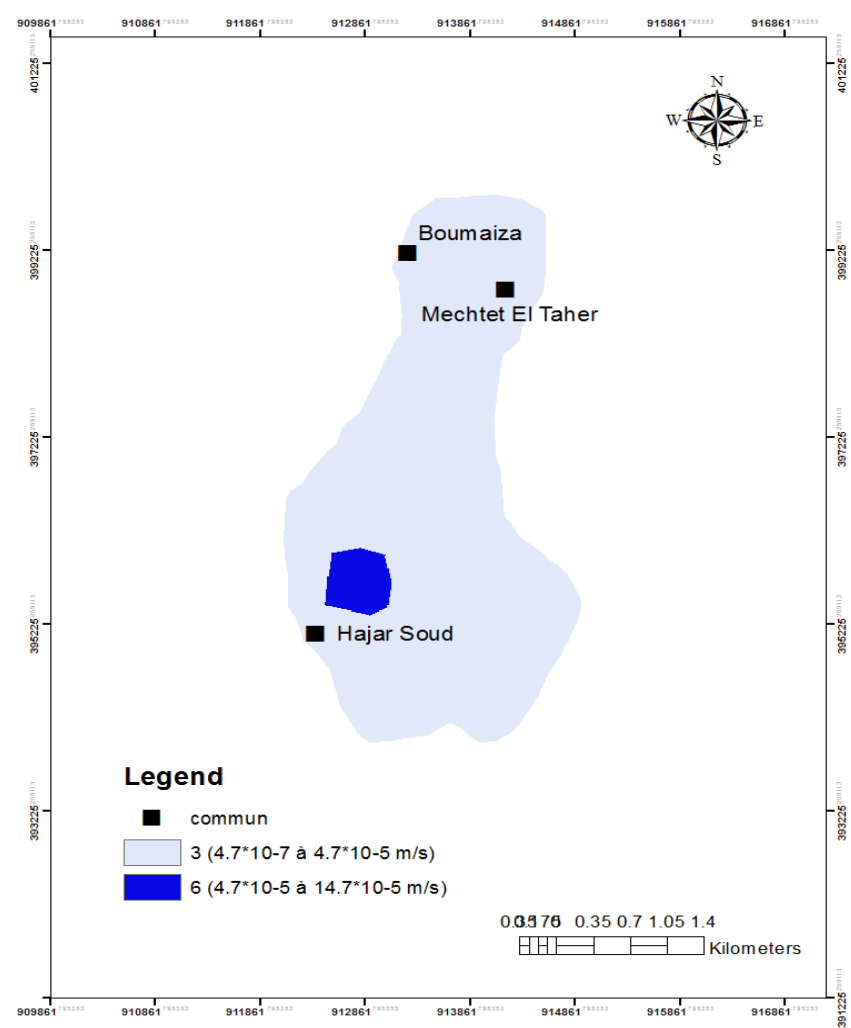

Figure 9. Hydraulic conductivity map in study area

\subsection{Interpretation of the DRASTIC pollution vulnerability map}

The result of the superposition of the seven preceding parameters gives the vulnerability map to the pollution (Fig. 10); it identifies a medium vulnerability marked on the whole aquifer of the Boumaiza plain, which is due to the average permeability and texture of the unsaturated zone, a type of soil of which they essentially form clays that limit the risk of infiltration of pollutants into the groundwater. This class is characterized by depths ranging from 2 to $10 \mathrm{~m}$, so pollutants do not take a long time to reach the groundwater. 


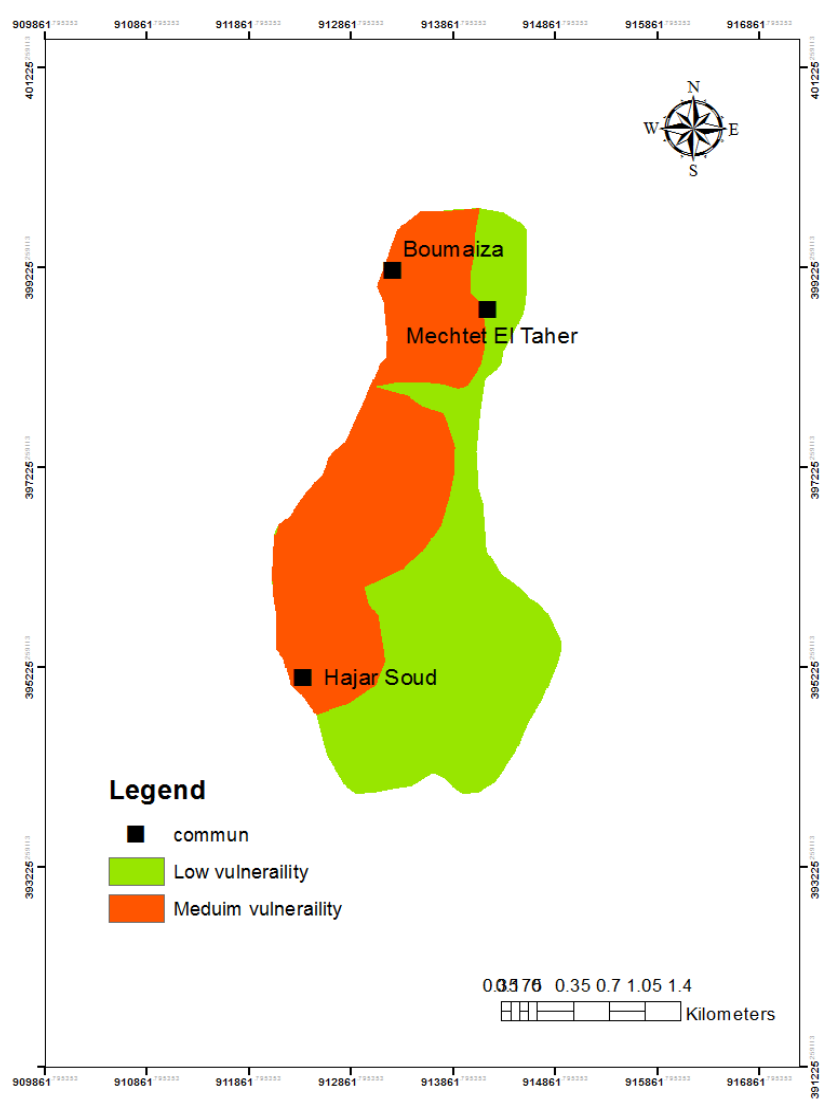

Figure 10. DRASTIC Vulnerability map

\section{CONCLUSION}

The analysis of the DRASTIC vulnerability map to groundwater pollution (Fig.10) shows that the Meduim vulnerability class occupies of the order of $52 \%$ of study area. But the low class represents approximately $48 \%$ of the study area regarding the hydrogeology of the Boumaiza plain aquifer, it will be necessary to:

- Regularly carry out campaigns to measure piezometric levels, physicochemical measurements and chemical analyzes at the level of the Boumaiza plain, which has a weak database.

- Take an interest in the problems related to aquifer recharge and wadi flow measurements. 
- The installation of hydrometric stations along the large wadis of the plain.

- The establishment of a program that helps us to minimize groundwater pollution with the integration of a tracing to see its spread, in order to propose solutions for the decontamination of contaminated areas.

- The implementation of a plan for evacuation of urban wastewater.

- Install protective perimeters around catchment works and on the preservation of water resources.

\section{References}

Abdeslam, I., Fehdi, C., Djabri, L., (2017), Application of drastic method for determining the vulnerability of an alluvial aquifer: Morsott-El Aouinet north east of Algeria: using arcgis environment, Scie Direct Energy Proced 119/308-317, https://doi.org/10.1016/j.egypro.2017.07.114

Aller, L., Bennet. T., Lehr, J.H., Petty, R.J., Hackett, G., (1987), DRASTIC: a standardized system for evaluating groundwater pollution potential using hydrogeological setting, US Env. Protection Agency, 163

Attoui, B., Benrabah, S., Majour, H., Zai,r N. (2017),,Assessment of groundwater vulnerability to pollution using the Kherici's method in the Talezza plain Collo region (NE Algeria), Journal of Water and Land Development..33 23-30, DOI: 10.1515/jwld-2017-0015.

Attoui B.,(2014), Etat de la vulnérabilité à la pollution des eaux des grands réservoirs d'eau souterraines de la région d'Annaba-El-Tarf et identification des sites d'enfouissement de déchets. Doctoral thesis, Annaba University, 1-100.

Attoui, B., Kherci, N., Bousnoubra, H.., (2012), State Of Vulnerability To Pollution Of The Big Reservoirs Of Groundwater In The Region Of Annaba-Bouteldja (NE Algeria), Geographia Technica., 2, 1-13, Mobilization-and-management-of-thewater-resources-in-the-North-east-of-Algeria.pdf (researchgate.net)

Baalousha, H., (2010), Assessment of a groundwater quality monitoring network using vulnerability mapping and geostatistics: a case study from Heretaunga Plains, New Zealand, Agric Water Manage, 97, pp. 240-246, https://doi.org/10.1016/j.agwat.2009.09.013

Chaoui, W., Attoui, B., Benhamza, M., Bouchami, T., Alimi, L. (2015), Water quality of the plain of El-Hadjar wilaya of Annaba (Northeast Algeria), Energy Procedia. 741174 - 1181, https://doi.org/10.1016/j.egypro.2015.07.760

Detay, M. (1997), La gestion active des aquifers, Masson, 145p.

Foster, S.S.D. (1987), Fundamental concepts in aquifer vulnerability, pollution risk and protection strategy, in: van Duijvenbooden W., van Waegeningh H.G. (eds), TNO Committee on Hydrological Research, Hague, Vulnerability of soil and groundwater to pollutants, Proc Inf 38:69-86, http://pascalfrancis.inist.fr/vibad/index.php?action=getRecordDetail\&idt=7424894

Hadj-Said, S. (2007), Contribution à l'étude hydrogéologique d'un aquifère en zone cotière: cas de la nappe de Guerbes, Doctoral thesis, Annaba University, 1-100. 
Nahin, K.T.K., Basak, R. \& Alam, R. (2019), Groundwater Vulnerability Assessment with DRASTIC Index Method in the Salinity-Affected Southwest Coastal Region of Bangladesh: A Case Study in Bagerhat Sadar, Fakirhat and Rampal. Earth Syst Environ, doi:10.1007/s41748-019-00144-7.

Sathees, K., Thirumalaivasan, D., Radhakrishnan, N. (2014), GIS Based Assessment of Groundwater Vulnerability Using Drastic Model, Arab J Sci Eng, 39 pp. 207-216, DOI: 10.1007/s13369-013-0843-3.

(C) 2020 by the authors. Licensee UAIC, Iasi, Romania. This article is an open access article distributed under the terms and conditions of the Creative Commons Attribution (CC BY-NC-ND) license (https://creativecommons.org/licenses/by-nc-nd/4.0). 